\title{
24 AGLE SOFTWARE DEVELOPMENT METHODS: When and Why Do They Work?
}

\author{
Balasubramaniam Ramesh \\ Georgia State University \\ Atlanta, GA U.S.A. \\ Pekka Abrahamsson \\ VTT Electronics \\ Oulu, Finland \\ Alistair Cockburn \\ Humans and Technology \\ Salt Late City, UT U.S.A.
}

Kalle Lyytinen Case Western Reserve University

Cleveland, OH U.S.A.

Laurie Williams

North Carolina State University Raleigh, NC U.S.A.

Agile software development challenges traditional software development methods. Rapidly changing environments, evolving requirements, and tight schedule constraints require software developers to take a fast cycle approach to the process of software development. Agile software development occurs in a dynamic and learning environment rather than in a mature and standardized software market (Cockburn 2001). Agile methods support shorter project lifecycles in order to respond to complex, fast-moving, and competitive marketplaces. The features of the system emerge throughout the development process, while heavily relying on feedback from the customer.

The rise of software development on Internet time has created tremendous interest among practitioners in agile development. Organizational agility, the ability to react quickly and flexibly to environmental or market changes, is an intended outcome of the 
use of agile methods (Goldman et al. 1995; Newman et al. 2000). Best known agile methods include eXtreme Programming (Beck et al. 1999), SCRUM (Schwaber and Beedle 2002), feature-driven development (Palmer and Felsing 2002), dynamic systems development method (Stapleton 1997), Crystal family (Cockburn 2001), and agile modeling (Ambler 2002). Variations of accelerated software development techniques have been presented as Internet time development (Cusumano and Yoffie 1999), Internet speed development (Baskerville et al. 2001), short cycle time development (Baskerville and Pries-Heje 2004), agile development (Aoyama 1998), Web development (Vidgen 2002), high speed development (Baserkerville et al. 2003), etc.

Although there is strong interest among researchers and practitioners on the use of agile methods, current knowledge on their applicability and effectiveness is fragmented and limited to the specific aspects of agile development. The applicability of the agile approach is constrained by several factors such as project size and type, experience level of project personnel, and committed customers. Beyond a few case studies and surveys (e.g., Grenning 2001; Rumpe and Schrder 2002), the effectiveness and applicability of agile methods have been the subject of debate (Boehm 2002). Organizations are reluctant to adopt agile methods unless they are convinced by the benefits of taking this new approach (Lindvall et al. 2002).

The panel will address the ongoing debate in the software development community on the applicability and effectiveness of agile methods by addressing the topic: "Agile Software Development Methods: When and Why Do They Work?" The panel will explore the characteristics of the organizational and project environment as well as the variety of practices that make agile methods successful.

Balasubramaniam Ramesh will introduce the panel and briefly explain the ongoing debate on the applicability of agile methods.

Pekka Abrahamsson will briefly compare the characteristics of popular agile methods and identify the common features of these methods and how they contribute to successful projects.

Alistair Cockburn will describe how specific agile practices have been successfully employed in industrial practice and provide insights into the nature of the project environments in which agile methods are appropriate.

Kalle Lyytinnen will discuss how discuss how agile methods may provide dynamic capabilities and foster hyper-learning to achieve agility.

Lau rie Williams will discuss how specific practices such as pair programming lead to desired project outcomes such as fewer code defects, shorter cycle time, and higher job satisfaction.

Each of the panelists will also identify the project environments in which agile methods are unlikely to be successful and suggest the characteristics of environments where they are appropriate.

\section{REFERENCES}

Ambler, S. W. Agile Modeling, New York: John Wiley and Sons, 2002.

Aoyama, M. "Web-Based Agile Software Development," IEEE Software (15:6), 1998, pp. 55-65. 
Baskerville, R., Levine, L., Pries-Heje, J., Ramesh, B., and Slaughter, S. "How Internet Software Companies Negotiate Quality," IEEE Computer (34:5), 2001, pp. 51-57.

Baskerville, R., and Pries-Heje, J. "Short Cycle Time Systems Development," Information Systems Journal (14:2), 2004, pp. 237-264.

Beck, K., Hannula, J., Hendrickson, C., Wells, D., and Mee, R. "Embracing Change with Extreme Programming," IEEE Computer (32:10), October 1999, pp. 70-77.

Boehm, B. "Get Ready for Agile methods, with Care," IEEE Computer (35:1), 2002, pp. 64-69.

Cockburn, A. "Agile Software Development," in The Agile Software Development Series, A. Cockburn and J. Highsmith (Eds.), Boston: Addison Wesley Longman, 2001.

Cusumano, M., and Yoffie, D. "Software Development on Internet Time," Computer (32:10), 1999, pp. 60-69.

Goldman, S., Nagel, R., and Preiss, K. Agile Competitors and Virtual Organizations, New York: Van Nostrand Reinhold, 1995.

Grenning, J. "Launching XP at a Process-Intensive Company," IEEE Software (18:6), 2001, pp 3-9.

Lindvall, M., Basili, V., Boehm, B., Costa, P., Dangle, K., Shull, F., Tesoriero, R., Williams, L., and Zelkowitz, M. "Empirical Findings in Agile Methods," in Proceedings of the XP/Agile University 2002: Second XP Universe and First Agile Universe Conference, Chicago: Springer-Verlag GmbH., 2002, pp. 197-207.

Newman, W., Podgurski, A., Quinn, R., Merat, F., Branicky, M., Barendt, N., Causey, G., Haaser, E., Kim, Y., Swaminathan, J., and Velasco, V. "Design Lessons for Building Agile Manufacturing Systems," IEEE Transactions on Robotics and Automation (16:3), 2000, pp. 228-238.

Palmer, S. R., and Felsing, J. M. A Practical Guide to Feature-Driven Development, Upper Saddle River, NJ: Prentice-Hall, 2002

Rumpe, B., and Schrder, A. "Quantitative Survey on Extreme Programming Project," in Proceedings of the Third International Conference on eXtreme Programming and Agile Processes in Software Engineering, Alghero, Italy, 2002, pp. 95-100 (available online at http://www.xp2003.org/xp2002/atti/Rumpe-Schroder--QuantitativeSurveyonExtremeProgrammingProjects.pdf; accessed February 18, 2005).

Schwaber, K., and Beedle, M. Agile Software Development with SCRUM, Upper Saddle River, NJ: Prentice-Hall, 2002

Stapleton, J. DSDM: The Method in Practice, Reading, MA: Addison Wesley, 1997. Vidgen, R. "Constructing a Web Information Systems Development Methodology," Information Systems Journal (12:3), 2002, pp. 247-261. 